\title{
Aplikasi Pencarian Tempat Indekos dengan Metode Rekomendasi Social Trust Path
}

\author{
Arthur William $^{1}$, Rendy Christian ${ }^{2}$, Riyandi ${ }^{3}$, Putra Edi Mujahid ${ }^{4 *}$ \\ Fakultas Teknologi dan Ilmu Komputer, Program Studi Sistem Informasi, Universitas Prima Indonesia, Medan, Indonesia \\ Email: ${ }^{1}$ Arthurwilliamleonardo@gmail.com, ${ }^{2}$ Riyandi1611@gmail.com, ${ }^{3}$ rendychris11@gmail.com, \\ 4,*putraedimujahid@unprimdn.ac.id
}

\begin{abstract}
Abstrak-Indekos atau kos adalah sebuah jasa yang menawarkan sebuah kamar atau tempat untuk ditinggali dengan sejumlah pembayaran tertentu untuk setiap periode tertentu (umumnya pembayaran per bulan).Saat ini, kebanyakan indekos yang tersedia di kota Medan masih menggunakan sistem manual dalam melakukan pencatatan secara manual dalam mencatat transaksi antara penghuni indekos dengan pemilik indekos. Penerapan sistem manual ini sering menghadapi berbagai masalah, seperti belum adanya sistem pemberitahuan mengenai jatuh tempo pembayaran kepada penghuni, susahnya memberikan keluhan kepada pemilik dan penghuni tidak dapat mengetahui apakah keluhannya telah diketahui dan ditanggapi oleh pemilik atau belum, pemilik indekos harus mengecek catatannya untuk mengetahui penghuni mana yang belum melunasi pembayarannya, sehingga sering diperlukan waktu yang lama untuk memperoleh informasi tersebut.Untuk lebih mendukung kinerja dari marketplace ini, maka akan ditambahkan fitur rekomendasi pada aplikasi marketplace tersebut. Metode yang dapat digunakan adalah metode social trust path.Metode social trust pathadalah metode perhitungan nilai tingkat kepercayaan dari sesuatu dengan bergantung pada tingkat kepercayaan dari user yang memberikan pernyataan tersebut.Tools yang digunakan untuk melakukan analisis dan desain adalah use casediagram. Website ini dibangun dengan menggunakan bahasa pemrograman $P H P$ dan database MySQL.Hasil dari penelitian ini adalah aplikasi rekomendasi tempat indekos berbasis webyang dapat digunakan untuk memberikan informasi tempat indekos bagi pemakai.
\end{abstract}

Kata Kunci: Sistem Rekomendasi; Tempat Indekos; Metode Social Trust Path

Abstract-Boarding house is a service that offers a room or a place to live in with a certain amount of payment for a certain period (generally payments per month). Currently, most boarding houses available in Medan still use a manual system to manually record transactions between homestay residents and boarding owners. The application of this manual system often faces various problems, such as the absence of a notification system regarding payment due dates to residents, the difficulty of making complaints to owners and residents cannot find out whether their complaints have been known and responded to by the owner or not, boarding owners must check their records to find out residents which ones have not paid off, so it often takes a long time to obtain the information. To further support the performance of this marketplace, a recommendation feature will be added to the marketplace application. The method that can be used is the Social Trust Path method. The Social Trust Path method is a method of calculating the value of the confidence level of something depending on the level of trust of the user who gives the statement. The tools used to perform analysis and design are use case diagrams. This website is built using PHP coding and MySQL database. The result of this research is a webbased boarding house recommendation application that can be used to provide boarding place information for users.

Keywords: Recommendation System; Boarding House; Social Trust Path Method

\section{PENDAHULUAN}

Seiring dengan semakin banyaknya masyarakat yang merantau demi menuntut ilmu ataupun bekerja, semakin banyak bermunculan tempat tinggal sementara yang sering disebut sebagai indekos, yang menawarkan sebuah kamar atau tempat untuk ditinggali dengan sejumlah pembayaran tertentu untuk setiap periode tertentu (umumnya pembayaran per bulan). Indekos ini sering dilengkapi dengan berbagai fasilitas seperti kamar mandi, tempat tidur, kipas, lemari dan sebagainya untuk menarik perhatian calon penghuni.

Saat ini, kebanyakan indekos yang tersedia di kota Medan masih menggunakan sistem manual dalam mencatat transaksi antara penghuni dengan pemilik. Penerapan sistem ini sering menghadapi berbagai masalah, seperti pemilik harus mengecek catatannya untuk mengetahui penghuni mana yang belum melunasi pembayarannya, sehingga sering diperlukan waktu yang lama untuk memperoleh informasi tersebut. Pada sistem ini, pemilik sering kesulitan dalam memperoleh informasi mengenai pembayaran biaya sewa, sehingga pemilik tidak dapat memperoleh informasi mengenai penghuni yang belum melunasi pembayaran biaya sewa dan penghuni yang sering telat dalam melunasi pembayarannya. Selain itu, pemilik juga kesulitan dalam mempromosikan tempat indekosnya dan sering harus mengeluarkan biaya yang banyak untuk menerbitkan iklan di berbagai media cetak dan media sosial. Permasalahan juga dihadapi oleh masyarakat calon penghuni, dimana masyarakat kesulitan dalam mencari tempat indekos yang sesuai dengan kriteria yang diinginkannya dan kondisi keuangannya.

Untuk lebih mendukung kinerja dari sistem indekos ini, maka akan ditambahkan fitur rekomendasi pada aplikasi tersebut.Sistem rekomendasi merupakan fitur yang banyak digunakan pada perangkat lunak zaman sekarang[1]. Metode yang dapat digunakan adalah metode Social Trust Path. Metode ini mengkombinasikan pendekatan regulasi sosial yang berhubungan dengan informasi jaringan sosial untuk memperoleh sistem rekomendasi dengan informasi kepercayaan antara user. Data kepercayaan dan rating akan digunakan untuk memprediksi nilai pada matriks user-item. Berdasarkan hubungan pertemanan, akan dibuat social network. Metode social trust path akan menghitung korelasi user-item, rumusan kalkulasi kepercayaan dan regulasi sosial[2].

Beberapa penelitian sejenis yang pernah dilakukan sebelumnya, seperti Sistem Informasi Indekos Berbasis Web [3]. Hasil dari sistem ini pencari indekos dapat mencari indekos berdasarkan kategori, wilayah dan harga, pemilik 
indekos dalam memasarkan indekosnya terlebih dahulu harus melakukan registrasi agar bisa menginput data indekosnya, admin dapat mengelola data indekos dan data user. Sistem ini telah dibuat dan terkomputerisasi secara online [3].

Penelitian lainnya seperti Rancang Bangun Sistem Informasi Rumah Kost dan Kontrakan Teluk Kuantan [4].Sistem ini menawarkan kemudahan bagi sipencari rumah kost dan kontrakan untuk melakukan penyewaan. Begitu juga dengan pemilik kost, maka dengan mudah menawarkan rumah kost dan kontrakan yang dimiliki agar dapat disewa dan dihuni oleh sipencari rumah kost, tentunya pembuat sistem juga akan mendapatkan keuntungan dari setiap transaksi yang dilakukan. Sistem informasi ini, memberikan gambaran jelas kepada si pencari rumah kost dan kontrakan dalam memilih hunian yang mereka lihat di halaman sistem informasi inisesuai dengan selera dan kebutuhan mereka masingmasing [4].

Penelitian lainnya yaitu Perancangan Sistem Informasi Pencarian Dan Pemesanan Rumah Kos Berbasis Web (Studi Kasus: Kota Bandar Lampung) [5]. Hasil pengujian kualitas menggunakan ISO 9126 aspek fungsionality yang menunjukkan bahwa sistem melakukan $100 \%$ fungsinya dengan benar dan hasil pengujian kebutuhan user menggunakan ISO 9126 aspek usability diperoleh nilai persentase sebesar 88.36\% [5].

Penelitian lainnya yaitu Aplikasi Pencarian dan Penyewaan Rumah Kost Berbasis Web dan Android [6]. Permasalahan dalam mencari rumah kost tersenbut mendorong pembuatan aplikasi pencarian dan penyewaan rumah kost berbasis Web dan mobile Android dengan menggunakan metode penelitian terapan dengan diagram fishbone untuk menganalisis kebutuhan pencari dan pemilik rumah kost. Pencari terbantu dalam melakukan pencarian dan penyewaan rumah kost yang diinginkan dan pemilik terbantu dalam melakukan promosi rumah kost [6].

\section{METODOLOGI PENELITIAN}

\subsection{Tahapan Penelitian}

Metodologi pengembangan sistem yang digunakan dalam penelitian ini mengacu pada metodologi System Development Life Cycle (SDLC) dengan tahapan-tahapan sebagai berikut:

1. Mengidentifikasi masalah, peluang, dan tujuan

Pada tahap ini, penulis mencari tahu apa yang menjadi permasalahan pada sistem indekos yang sedang berjalan, serta apa peluang dan tujuan dari hasil perancangan aplikasi web.

2. Menentukan syarat-syarat informasi

Pada tahap ini, penulis mengkaji lebih dalam masalah yang telah diidentifikasi pada tahap sebelumnya dan menentukan syarat-syarat informasi yang dibutuhkan dengan mengkaji kembali sistem yang berjalan saat ini di indekos. Teknik pengumpulan data yang digunakan adalah:

a. Studi Kepustakaan dan Internet

Untuk mengumpulkan data yang berkaitan dengan topik yang akan dibahas dilakukan dengan cara membaca buku-buku literatur maupun sumber daya yang ada di internet. Selanjutnya menganalisis aplikasi sejenis sebagai bahan referensi dalam pengembangan sistem usulan.

b. Observasi

Dilakukan dengan mengamati secara langsung sistem yang berjalan saat ini di indekos.

3. Menganalisis kebutuhan sistem

Kegiatan-kegiatan yang dilakukan pada tahap ini adalah:

a. Merancang flowchart dari metode Social Trust Path.

b. Merancang proses sistem usulan dengan menggunakan use case diagram.

4. Merancang sistem yang direkomendasikan

Kegiatan-kegiatan yang dilakukan pada tahap ini adalah:

a. Merancang user interface dari website usulan.

b. Merancang database yang akan digunakan oleh sistem usulan yang terdiri dari struktur tabel dan hubungan antar tabel dengan menggunakan DBMS MySQL.

\subsection{Sistem Rekomendasi}

Sistem rekomendasi adalah sebuah alat perangkat lunak dan teknik-teknik yang menyediakan saran untuk item-item yang paling memungkinkan menarik untuk pengguna tertentu[7].

\subsection{Social Trust Path}

Aplikasi pencarian tempat indekos berbasis web ini menggunakan metode social trust path untuk melakukan proses pencarian dan pemilihan tempat indekos yang sesuai dengan kriteria yang diinginkan oleh user. Algoritma Social Trust Path termasuk jenis algoritma Collaborative Filtering, dimana algoritma Social Trust Path akan memberikan rekomendasi kepada user dengan berdasarkan pada tingkat kepercayaan dari user kepada user lainnya[8].

\subsection{Proses Kerja Social Trust Path}

Pada bagian ini akan ditunjukkan proses pengolahan data dari kedua jenis hubungan user yaitu hubungan pemberian rating dan pertemanan sampai pada pemanfaatan hasil penggabungan dari kedua jenis hubungan tersebut untuk 
memprediksi nilai rating pada suatu tempat indekos melalui metode Social trust path. Masukan untuk metode ini berupa sebuah tabel dataset berukuran yang berisi sejumlah nilai rating yang diberikan oleh orang user terhadap sebuah tempat indekos beserta unipartite graph yang merepresentasikan relasi pertemanan antar user.

Metode Social trust path akan mengolah data input tersebut dengan menghitung kemiripan antara user berdasarkan rating dan juga kemiripan user berdasarkan pertemanan[1]. Hasil rating tersebut akan dilakukan proses normalisasi. Setelah itu, akan dilakukan proses penggabungan basis kemiripan antar user tersebut dengan menggunakan parameter $\alpha$. Cara penentuan parameter $\alpha$ dapat ditentukan secara manual ataupun ditentukan secara otomatis (auto) berdasarkan data rating yang dimasukkan. Kemudian, akan diprediksi nilai rating untuk setiap tempat indekos dan akan diurutkan setiap tempat indekos berdasarkan nilai rating secara menurun. Terakhir, akan dihasilkan daftar rekomendasi tempat indekos. Proses kerja dari aplikasi website Implementasi Metode Social trust path pada Sistem Rekomendasi Tempat indekos ini dapat digambarkan dalam bentuk flowchart seperti terlihat pada gambar berikut ini :

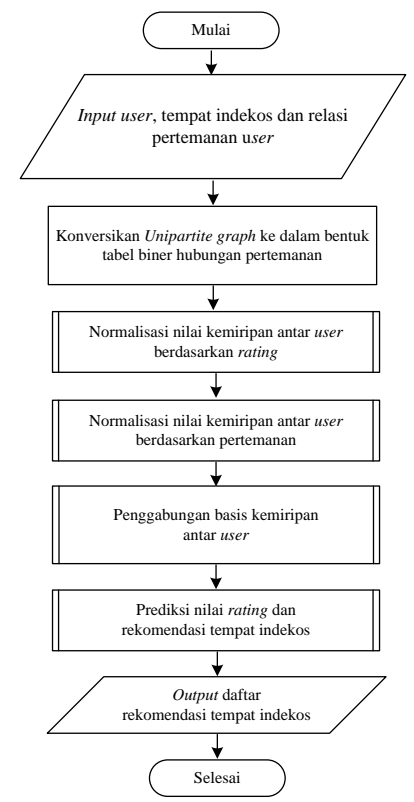

Gambar 1.Flowchart Sistem

Aplikasi rekomendasi tempat indekos berbasis web ini akan digunakan oleh tiga jenis pemakai (user), yaitu administrator, user pemilik indekos dan user. Proses kerja dari setiap jenis pemakai ini dapat dirincikan sebagai berikut:

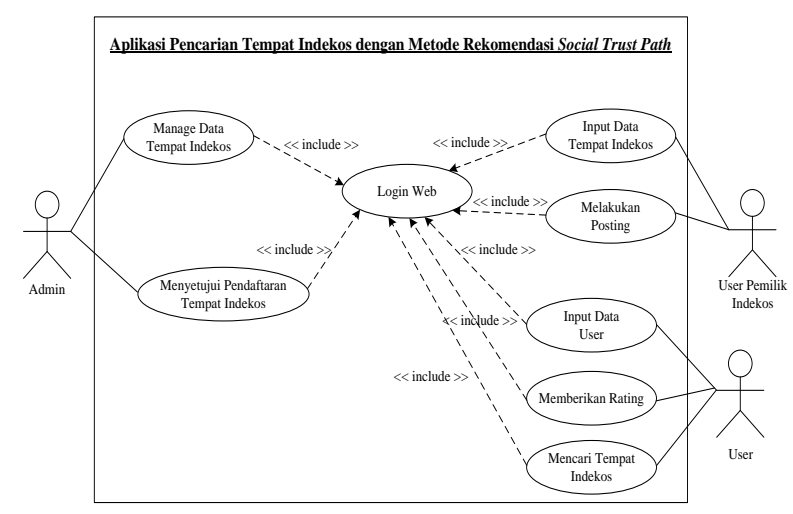

Gambar 2. Use Case Diagram dari bagian Web

\section{HASIL DAN PEMBAHASAN}

Untuk menguji tingkat akurasi dari prediksi rating dengan menggunakan metode social trust path, maka ditetapkan beberapa rating yang sebelumnya telah diberikan oleh user $u$ terhadap tempat indekos $f(u, f)$, di antaranya: $(35,1),(40,3),(61,2),(98,4)$ dan $(106,5)$ akan dikosongkan kembali.

Tabel 1. RatingUser-Tempat indekos

\begin{tabular}{cccccc}
\hline User, Tempat indekos & 1 & 2 & 3 & 4 & 5 \\
\hline 35 & - & 3 & 2 & 2 & 4 \\
40 & 4 & 2 & - & 4 & 3 \\
\hline
\end{tabular}




\begin{tabular}{cccccc}
\hline User, Tempat indekos & 1 & 2 & 3 & 4 & 5 \\
\hline 61 & 3 & - & 4 & 2 & 2 \\
98 & 2 & 3 & 1 & - & 5 \\
106 & 1 & 4 & 2 & 5 & - \\
\hline
\end{tabular}

Relasi pertemanan antar user dengan nilai biner mewakili antar suatu user memiliki relasi pertemanan dan nilai biner menunjukkan antar suatu user tidak memiliki relasi pertemanan, yang dapat dilihat pada tabel 2 berikut :

Tabel 2. Hubungan Pertemanan antar User

\begin{tabular}{cccccc}
\hline $\begin{array}{c}\text { User, } \\
\text { User }\end{array}$ & 35 & 40 & 61 & 98 & 106 \\
\hline 35 & 0 & 0 & 0 & 1 & 1 \\
40 & 0 & 0 & 1 & 0 & 1 \\
61 & 0 & 1 & 0 & 0 & 0 \\
98 & 1 & 0 & 0 & 0 & 0 \\
106 & 1 & 1 & 0 & 0 & 0 \\
\hline
\end{tabular}

Langkah awal dari metode Social trust path adalah menghitung rataan rating yang diberikan dari setiap user. Perolehan rataan rating setiap user pada tabel 3. dapat ditunjukkan sebagai berikut:

Tabel 3. RatingUser-Tempat indekos (Rataan Rating)

\begin{tabular}{ccccccc}
\hline User, Tempat indekos & 1 & 2 & 3 & 4 & 5 & Rataan \\
\hline 35 & - & 3 & 2 & 2 & 4 & 2.2 \\
40 & 4 & 2 & - & 4 & 3 & 2.6 \\
61 & 3 & - & 4 & 2 & 2 & 2.2 \\
98 & 2 & 3 & 1 & - & 5 & 2.2 \\
106 & 1 & 4 & 2 & 5 & - & 2.4 \\
\hline
\end{tabular}

Kemiripan antara user dengan user itu sendiri akan langsung diwakili nilai 1 sehingga perhitungan kemiripan ( $\mathrm{sim}$ ) dengan persamaan metrik cosine similarity hanya dilakukan untuk antar user $(u, v)$, diantaranya: $(35,40),(35,61),(35,98),(35,106),(40,61),(40,98),(40,106),(61,98),(61,106)$ dan $(98,106)$.

Untuk $\operatorname{sim}(35,40)$.

$$
\operatorname{sim}(35,40)=\frac{(3 \times 2)+(2 \times 4)+(4 \times 3)}{\sqrt{3^{2}+2^{2}+4^{2}} \times \sqrt{2^{2}+4^{2}+3^{2}}} \approx 0.675
$$

Untuk $\operatorname{sim}(98,106)$.

$$
\operatorname{sim}(98,106)=\frac{(2 \times 1)+(3 \times 4)+(1 \times 2)}{\sqrt{2^{2}+3^{2}+1^{2}} \times \sqrt{1^{2}+4^{2}+2^{2}}} \approx 0.378
$$

Hasil perhitungan seluruh kemiripan antar user berdasarkan hubungan pemberian rating dapat ditunjukkan sebagai berikut:

Tabel 4. Kemiripan antar User Berdasarkan Rating

\begin{tabular}{cccccc}
\hline $\begin{array}{c}\text { User, } \\
\text { User }\end{array}$ & 35 & 40 & 61 & 98 & 106 \\
\hline 35 & 1 & 0.675 & 0.606 & 0.864 & 0.667 \\
40 & 0.675 & 1 & 0.675 & 0.692 & 0.703 \\
61 & 0.606 & 0.675 & 1 & 0.557 & 0.539 \\
98 & 0.864 & 0.692 & 0.557 & 1 & 0.378 \\
106 & 0.667 & 0.703 & 0.539 & 0.378 & 1 \\
\hline
\end{tabular}

Tabel 4 diatas menunjukkan kemiripan antara user berdasarkan pada nilai rating tempat indekos yang dimasukkan. Seperti terlihat pada tabel 3 diatas, user 35 memiliki tingkat kemiripan sebesar $67.5 \%$ terhadap user 40 . Sementara itu, tingkat kemiripan antara user 35 dan user 98 adalah yang paling tinggi, yaitu dengan tingkat kemiripan sebesar $86.4 \%$.

Kemiripan antar user yang diperoleh melalui metrik cosine similarity umumnya memiliki nilai yang relatif tinggi dengan interval $[0.8,1]$. Normalisasi diperlukan untuk mendistribusikan nilai-nilai tersebut kembali ke dalam interval $[0,1]$ secara merata. Tahapan normalisasi mencakup perolehan rataan keseluruhan kemiripan antar user berdasarkan tabel 4, standar deviasi, dan pemakaian fungsi logistik sigmoid untuk mengubah nilai kemiripan kembali ke dalam interval $[0,1]$.

Tahapan Perolehan Rataan Kemiripan $(\mu)$ :

$$
\mu=\frac{1+0.675+\cdots+0.378+1}{25} \approx 0.709
$$

Tahapan Perolehan Standar Deviasi $(s)$ : 


$$
s=\sqrt{\frac{(1-0.709)^{2}+(0.675-0.709)^{2}+\cdots+(1-0.709)^{2}}{25-1}}
$$

Tahapan Normalisasi Kemiripan antar User:

Untuk $\operatorname{sim}(35,35)$.

$$
\operatorname{sim}(35,35)=\frac{1}{1+e^{-\left(\frac{1-0.709}{0.185}\right)}} \approx 0.8281
$$

Untuk $\operatorname{sim}(106,106)$.

$$
\operatorname{sim}(106,106)=\frac{1}{1+e^{-\left(\frac{1-0.709}{0.185}\right)}} \approx 0.8281
$$

Hasil normalisasi nilai pada tabel 4 dapat ditunjukkan pada tabel 5 bawah berikut:

Tabel 5. Normalisasi Kemiripan antar User Berdasarkan Rating

\begin{tabular}{cccccc}
\hline User, User & 35 & 40 & 61 & 98 & 106 \\
\hline 35 & 0.8281 & 0.4545 & 0.3652 & 0.6983 & 0.4446 \\
40 & 0.4545 & 0.8281 & 0.4545 & 0.478 & 0.493 \\
61 & 0.3652 & 0.4545 & 0.8281 & 0.3069 & 0.2861 \\
98 & 0.6983 & 0.478 & 0.3069 & 0.8281 & 0.1438 \\
106 & 0.4446 & 0.493 & 0.2861 & 0.1438 & 0.8281 \\
\hline
\end{tabular}

Tabel 5 diatas menunjukkan hasil normalisasi kemiripan antara user berdasarkan pada nilai rating tempat indekos yang dimasukkan. Proses normalisasi ini dilakukan untuk menghindari nilai 0 dan 1 dalam nilai kemiripan antara user. Seperti terlihat pada tabel 5 diatas, user 35 memiliki tingkat kemiripan sebesar $45.45 \%$ terhadap user 40 jika ditinjau dari tingkat kemiripan secara global.

Langkah selanjutnya adalah menghitung kemiripan antar user berdasarkan relasi pertemanan yang dijalin dengan user yang lain dengan menggunakan metrik friendTNS similarity. Bila user $u$ tidak menjalin hubungan pertemanan dengan user $v$, maka hubungkan kedua user tersebut dengan relasi pertemanan user lain melalui jalur tersingkat.

Untuk $\operatorname{sim}(35,40)$.

Dikarenakan user35 tidak menjalin hubungan pertemanan dengan user40, maka jalur tersingkat yang menghubungkan kedua user tersebut adalah melalui edge $(35,106)$ dan dilanjutkan dengan edge $(106,40)$. Proses perhitungan similarity antara user 35 dan user 40 adalah sebagai berikut:

$$
\begin{gathered}
\operatorname{sim}(35,40)=\operatorname{sim}(35,106) \times \operatorname{sim}(106,40) \\
\operatorname{sim}(35,40)=\frac{1}{2+2-1} \times \frac{1}{2+2-1} \approx 0.1111
\end{gathered}
$$

Untuk $\operatorname{sim}(98,106)$.

$$
\begin{aligned}
& \operatorname{sim}(98,106)=\operatorname{sim}(98,35) \times \operatorname{sim}(35,106,) \\
& \operatorname{sim}(98,106)=\frac{1}{1+2-1} \times \frac{1}{2+2-1} \approx 0.1665
\end{aligned}
$$

Hasil perhitungan seluruh kemiripan antar user berdasarkan hubungan pertemanan dapat ditunjukkan sebagai berikut:

Tabel 6. Kemiripan antar User Berdasarkan Pertemanan

\begin{tabular}{cccccc}
\hline User,User & 35 & 40 & 61 & 98 & 106 \\
\hline 35 & 0 & 0.1111 & 0.0555 & 0.5 & 0.3333 \\
40 & 0.1111 & 0 & 0.5 & 0.0555 & 0.3333 \\
61 & 0.0555 & 0.5 & 0 & 0.0277 & 0.1665 \\
98 & 0.5 & 0.0555 & 0.0277 & 0 & 0.1665 \\
106 & 0.3333 & 0.3333 & 0.1665 & 0.1665 & 0 \\
\hline
\end{tabular}

Tabel 6 diatas menunjukkan kemiripan antara user berdasarkan pada nilai pertemanan. Seperti terlihat pada tabel 6 diatas, user 35 memiliki tingkat kemiripan sebesar 11.11\% terhadap user 40. Sementara itu, tingkat kemiripan antara user 35 dan user 98 adalah sebesar 50\%. Kemiripan antar user yang diperoleh melalui metrik FriendTNS umumnya memiliki nilai yang relatif rendah dengan interval $[0,0.3]$. Normalisasi diperlukan untuk mendistribusikan nilai-nilai tersebut kembali ke dalam interval $[0,1]$ secara merata. Tahapan normalisasi mencakup perolehan rataan keseluruhan kemiripan antar user berdasarkan tabel 3.7., standar deviasi, dan pemakaian fungsi logistik sigmoid untuk mengubah nilai kemiripan kembali ke dalam interval $[0,1]$. 
Tahapan perolehan rataan kemiripan $(\mu)$ :

$$
\mu=\frac{0+0.1111+\cdots+0.1665+0}{25} \approx 0.1795
$$

Tahapan perolehan standar deviasi $(s)$ :

$$
s=\sqrt{\frac{(0-0.1795)^{2}+(0.1111-0.1795)^{2}+\cdots+(0.1665-0.1795)^{2}+(0-0.1795)^{2}}{25-1}}
$$

Tahapan normalisasi kemiripan antar user:

Untuk $\operatorname{sim}(35,35)$.

Untuk $\operatorname{sim}(106,106)$.

$$
\operatorname{sim}(35,35)=\frac{1}{1+e^{-\left(\frac{0-0.1795}{0.2465}\right)}} \approx 0.325579
$$

$$
\operatorname{sim}(106,106)=\frac{1}{1+e^{-\left(\frac{0-0.1795}{0.2465}\right)}} \approx 0.325579
$$

Hasil normalisasi nilai pada tabel 4 dapat ditunjukkan pada tabel 5 bawah berikut:

Tabel 7. Normalisasi Kemiripan antar User Berdasarkan Pertemanan

\begin{tabular}{cccccc}
\hline $\begin{array}{c}\text { User, } \\
\text { User }\end{array}$ & \multirow{2}{*}{35} & 40 & 61 & 98 & 106 \\
\hline 35 & 0.325579 & 0.431033 & 0.376801 & 0.785787 & 0.651035 \\
40 & 0.431033 & 0.325579 & 0.785787 & 0.376801 & 0.651035 \\
61 & 0.376801 & 0.785787 & 0.325579 & 0.34611 & 0.486769 \\
98 & 0.785787 & 0.376801 & 0.34611 & 0.325579 & 0.486769 \\
106 & 0.651035 & 0.651035 & 0.486769 & 0.486769 & 0.325579 \\
\hline
\end{tabular}

Tabel 7 diatas menunjukkan hasil normalisasi kemiripan antara user berdasarkan pada nilai pertemanan. Seperti terlihat pada tabel 4 diatas, user 35 memiliki tingkat kemiripan sebesar $43.10 \%$ terhadap user 40 .

Perolehan dua basis kemiripan antar user yaitu berdasarkan hubungan pemberian rating dan pertemanan dengan hasil yang ditunjukkan pada tabel 5 dan tabel 7. Selanjutnya digabungkan menjadi satu kesatuan dengan menggunakan metrik Social-Union itu sendiri.

Misalkan ditentukan $a=0.25$, maka:

Untuk $\operatorname{sim}(35,35)$.

$$
\operatorname{sim}(35,35)=(1-0.25) \times 0.325579+0.25 \times 0.8281 \approx 0.4512
$$

Untuk $\operatorname{sim}(106,106)$.

$$
\operatorname{sim}(106,106)=(1-0.25) \times 0.325579+0.25 \times 0.8281 \approx 0.4512
$$

Hasil penggabungan basis kemiripan antar user dapat ditunjukkan pada tabel bawah berikut:

Tabel 8. Penggabungan Basis Kemiripan antar User

\begin{tabular}{cccccc}
\hline $\begin{array}{c}\text { User, } \\
\text { User }\end{array}$ & 35 & 40 & 61 & 98 & 106 \\
\hline 35 & 0.4512 & 0.4369 & 0.3739 & 0.7639 & 0.5994 \\
40 & 0.4369 & 0.4512 & 0.703 & 0.4021 & 0.6115 \\
61 & 0.3739 & 0.703 & 0.4512 & 0.3363 & 0.4366 \\
98 & 0.7639 & 0.4021 & 0.3363 & 0.4512 & 0.401 \\
106 & 0.5994 & 0.6115 & 0.4366 & 0.401 & 0.4512 \\
\hline
\end{tabular}

Prediksi nilai rating untuk pasangan user-tempat indekos $(u, f)$ dapat ditunjukkan sebagai berikut: Untuk user 35 dan tempat indekos 1.

$$
\begin{gathered}
\hat{r}_{35,1}=2.2+\frac{0.4369 \times|4-2.6|+0.3739 \times|3-2.2|+0.7639 \times|2-2.2|+0.5994 \times|1-2.4|}{0.4369+0.3739+0.7639+0.5994} \\
\hat{r}_{35,1} \approx 3.075178 \approx 3
\end{gathered}
$$

Hasil prediksi nilai rating dapat ditunjukkan pada tabel bawah berikut:

Tabel 9. Prediksi Nilai Rating

\begin{tabular}{cccccc}
\hline $\begin{array}{c}\text { User, Tempat } \\
\text { indekos }\end{array}$ & 1 & 2 & 3 & 4 & 5 \\
\hline 35 & 3 & 3 & 2 & 2 & 4 \\
\hline
\end{tabular}


Journal of Information System Research (JOSH)

Volume 2, No. 4, Juli 2021

ISSN 2686-228X (media online)

Hal: 293-302

\begin{tabular}{cccccc}
\hline $\begin{array}{c}\text { User, Tempat } \\
\text { indekos }\end{array}$ & 1 & 2 & 3 & 4 & 5 \\
\hline 40 & 4 & 2 & 3 & 4 & 3 \\
61 & 3 & 3 & 4 & 2 & 2 \\
98 & 2 & 3 & 1 & 3 & 5 \\
106 & 1 & 4 & 2 & 5 & 4 \\
\hline
\end{tabular}

\subsection{Implementasi Program}

Berikut ini adalah tampilan hasil dari Aplikasi Pencarian Tempat Indekos dengan Metode Rekomendasi Social Trust Path. Tampilan Awal dari aplikasi ini dapat dirincikan sebagai berikut:

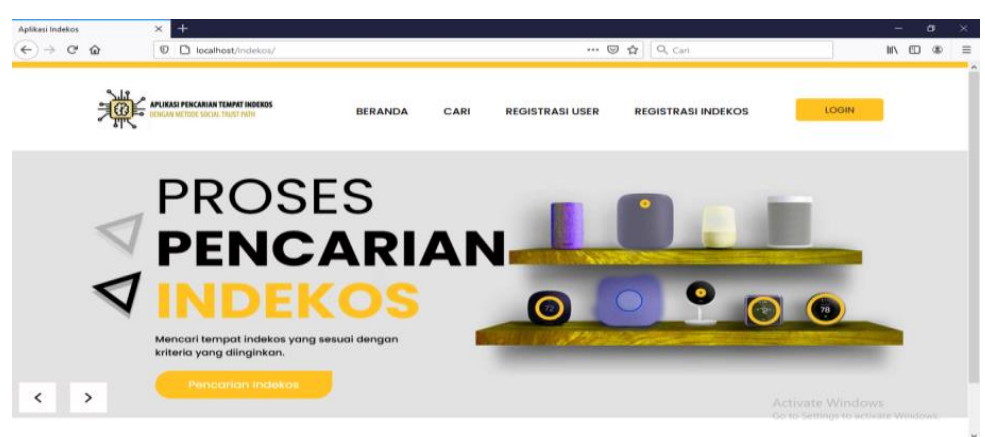

Gambar 3. Tampilan Awal

Tampilan Awal ini merupakan tampilan awal di saat user memasuki halaman web yang penulis bangun. Pada halaman awal ini, user dapat melihat berbagai informasi mengenai berbagai indekos yang terdapat di kota Medan. Agar dapat melakukan pemesanan, maka user harus melakukan login ke dalam sistem terlebih dahulu. Caranya adalah dengan mengklik link Login.Apabila user belum mendaftarkan diri ke dalam sistem, user harus melakukan registrasi terlebih dahulu dengan mengklik link Daftar User sehingga sistem akan menampilkan halaman Daftar User seperti terlihat pada gambar berikut:

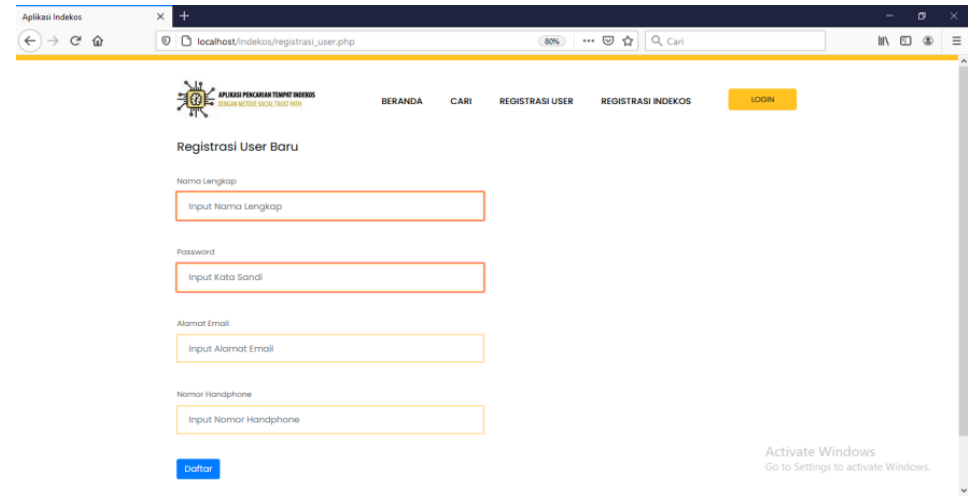

Gambar 4 .Tampilan Daftar User

Pada halaman Daftar User ini, user harus memasukkan semua datanya dengan valid. Data input ini yang akan digunakan dalam proses login ke dalam sistem. Apabila user telah memasukkan semua datanya maka user dapat mengklik tombol Simpan untuk menyimpan data input ke dalam database.

Setelah itu, user dapat melakukan login ke dalam sistem dengan mengklik link Login, sehingga sistem akan menampilkan halaman Login seperti terlihat pada gambar berikut:

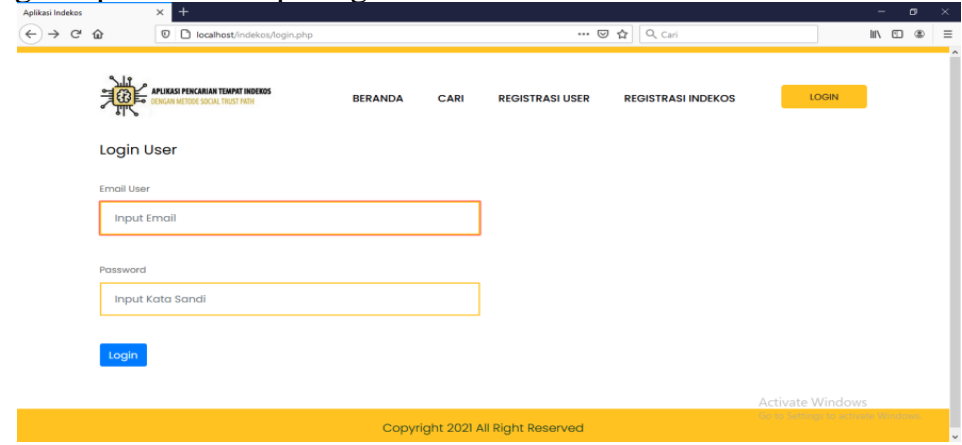

Gambar 5. Tampilan Login

Arthur William | https://ejurnal.seminar-id.com/index.php/josh/ | Page 299 Submitted: 28/06/2021; Accepted: 27/07/2021; Published: 31/07/2021 
Pada halaman website ini, user harus memasukkan data user yang valid agar user dapat menggunakan aplikasi yang dibuat. Apabila proses login berhasil, maka sistem akan menampilkan halaman Home dari sistem, seperti terlihat pada gambar 6 .

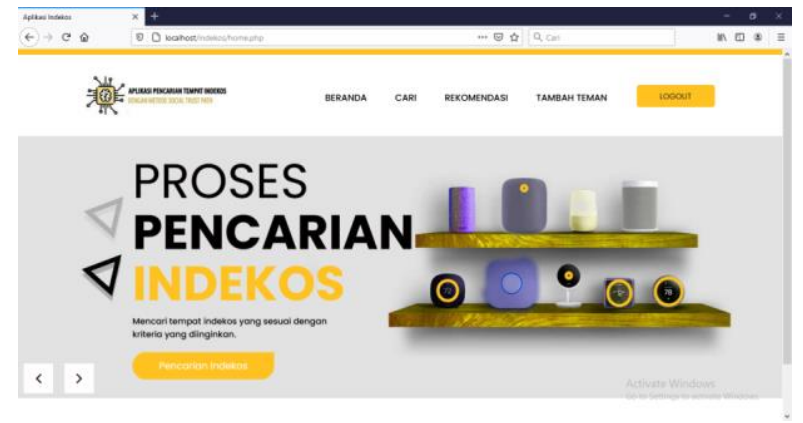

Gambar 6. Tampilan Halaman Home

Setelah melakukan login ke dalam sistem, maka user dapat melakukan pencarian tempat indekos yaitu dengan mengklik link Cari, sehingga sistem akan menampilkan halaman Cari seperti terlihat pada gambar berikut:

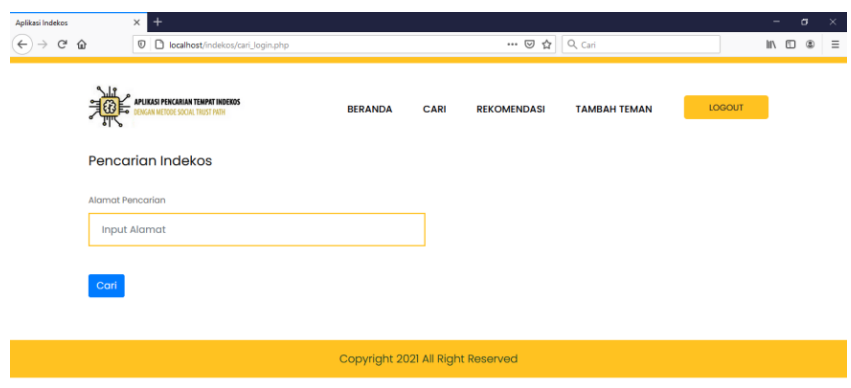

Gambar 7. Tampilan Halaman Cari

User dapat memilih kategori pencarian dan memasukkan kata pencarian yang diinginkan serta mengklik tombol Cari. Setelah itu, sistem akan menampilkan halaman Hasil Pencarian seperti terlihat pada gambar berikut:

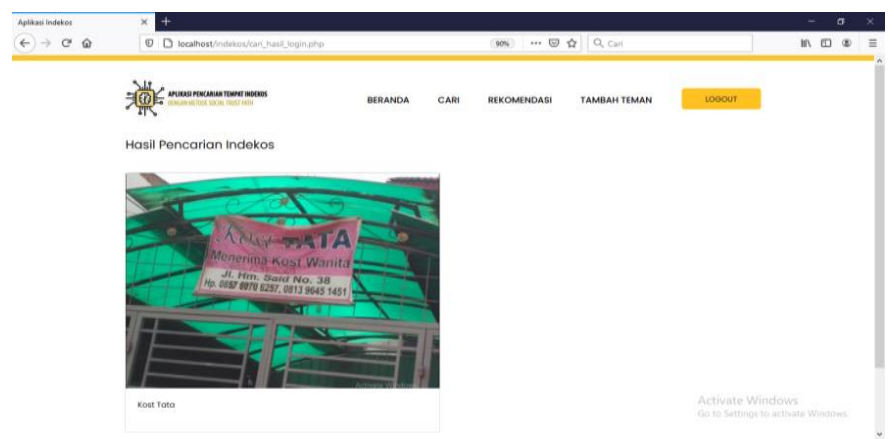

Gambar 8. Tampilan Halaman Hasil Pencarian

Apabila user ingin menampilkan hasil rekomendasi tempat indekos, maka user dapat mengklik link Rekomendasi sehingga sistem akan menampilkan halaman Rekomendasi seperti terlihat pada gambar berikut:

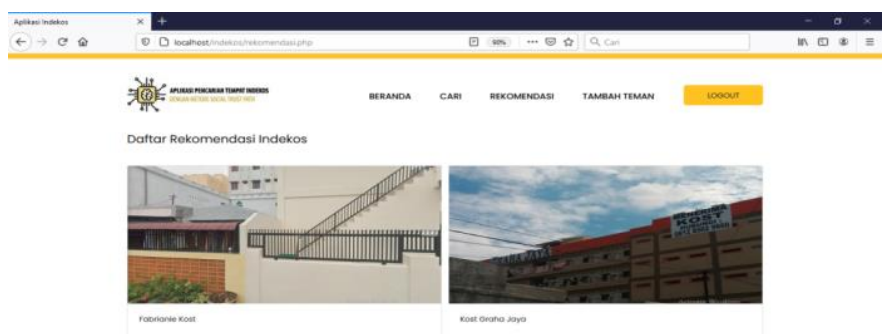

Gambar 9. Tampilan Halaman Rekomendasi

Arthur William | https://ejurnal.seminar-id.com/index.php/josh/ | Page 300 Submitted: 28/06/2021; Accepted: 27/07/2021; Published: 31/07/2021 
User dapat melihat informasi mengenai tempat indekos dengan mengklik gambar atau nama tempat indekos yang bersangkutan, maka sistem akan menampilkan halaman Info Tempat Indekos seperti terlihat pada gambar berikut:

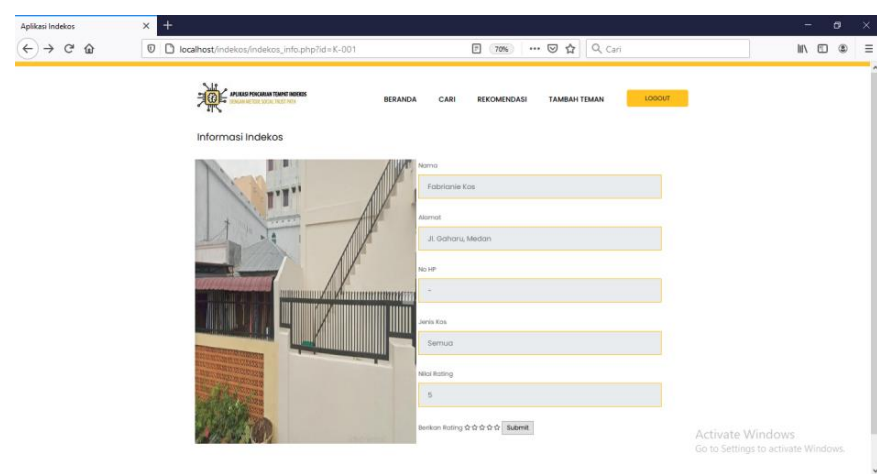

Gambar 10. Tampilan Halaman Info Tempat Indekos

Pada halaman info tempat indekos ini, user juga dapat memberikan rating kepada tempat indekos yang bersangkutan. Caranya adalah dengan mengklik bintang pada berikan rating dan klik tombol Submit. Sistem akan menyimpan nilai rating yang diberikan dan menghitung ulang nilai rating dari tempat indekos yang bersangkutan.

Terakhir, user dapat menambah teman dari user dengan mengklik link Tambah Teman sehingga sistem akan menampilkan halaman Tambah Teman seperti terlihat pada gambar berikut:

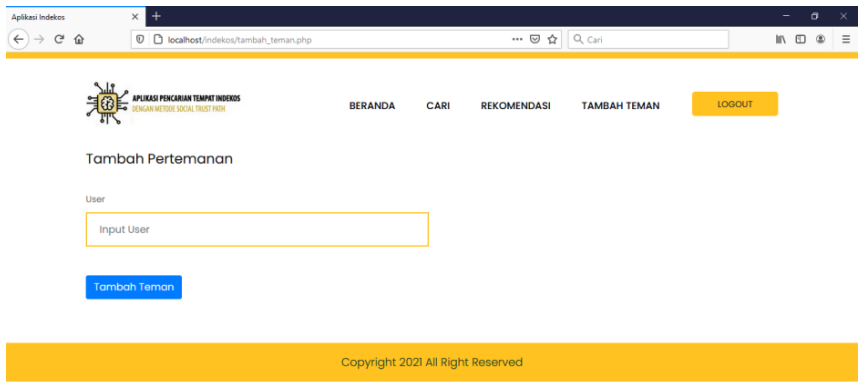

Gambar 11. Tampilan Halaman Tambah Teman

Selain tampilan berbasis website, user juga dapat mengakses aplikasi berbasis mobile. Pada saat pertama kali menjalankan Sistem Rekomendasi Indekos Menggunakan Social Trust Path berbasis mobile, maka halaman yang akan muncul pertama kali adalah halaman Login, yang dapat dilihat pada Gambar 4.11 berikut ini:

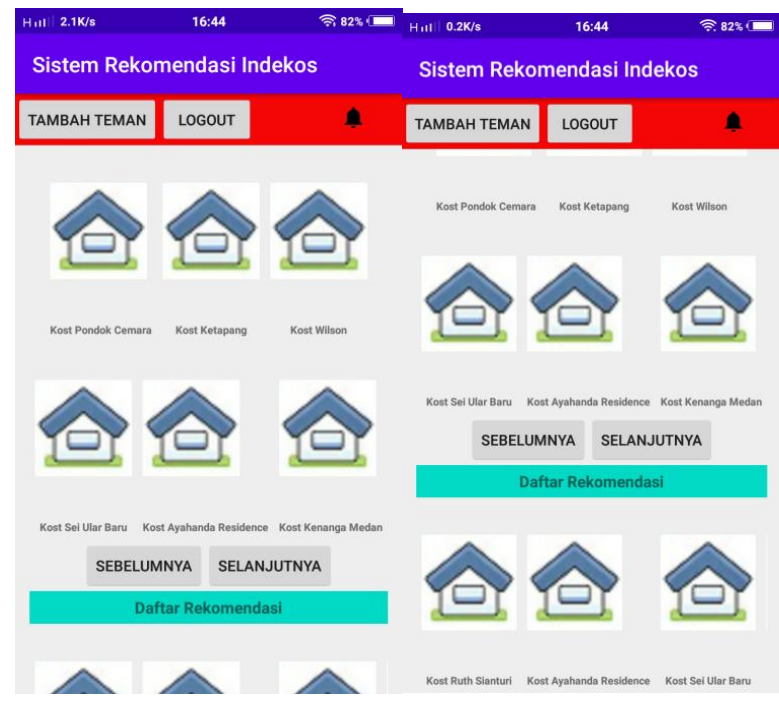

Gambar 12. Tampilan halaman home versi mobile

User tempat indekos juga dapat menggunakan Aplikasi Pencarian Tempat Indekos dengan Metode Rekomendasi Social Trust Path. User tempat indekos dapat mendaftarkan tempat indekosnya ke dalam sistem. Caranya adalah dengan mengklik link Daftar Indekos sehingga sistem akan menampilkan halaman berikut: 


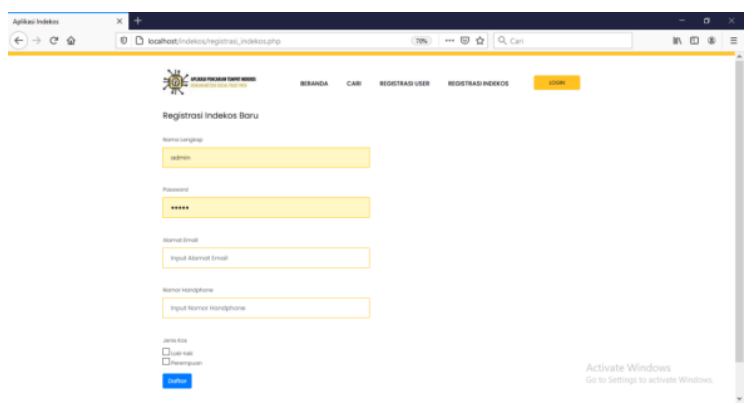

Gambar 13. Tampilan Halaman Daftar Tempat Indekos Baru

User tempat indekos dapat menambahkan post dari tempat indekosnya. Caranya adalah dengan mengklik link Tambah Post sehingga sistem akan menampilkan halaman Tambah Post seperti terlihat pada gambar berikut:

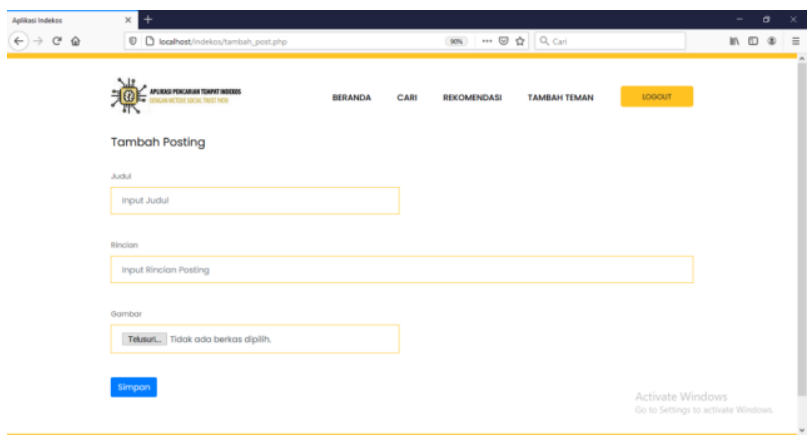

Gambar 14. Tampilan Halaman Tambah Post

\section{KESIMPULAN}

Selama dalam proses perancangan dan uji coba sistem informasi berbasis web ini, penulis dapat menarik beberapa kesimpulan, yaitu sistem informasi yang peneliti bangun bisa memberikan kemudahan bagi customer dalam melakukan pencarian tempat indekosdengan cepat. Design pada website ini peneliti atur dengan sedemikian rupa dengan maksud untuk memberikan suatu suasana yang ceria sehingga bisa menarik minat customer. Adapun saran-saran yang ingin penulis sampaikan sehubungan dengan pengembangan sistem ini, yaitu sistem dapat dikembangkan lebih lanjut dengan menambahkan keamanan pada sistem, sehingga data pemakai dapat lebih terjamin.Sistem dapat dikembangkan lebih lanjut sehingga mendukung proses pembayaran dengan kartu kredit ataupun dengan layanan pembayaran online lainnya, seperti paypal.Tampilan dapat lebih ditingkatkan lagi dengan menambahkan fitur animasi dan gambar-gambar lainnya sehingga website kelihatan lebih menarik lagi.

\section{REFERENCES}

[1] H. Ma and D. Che, "An Integrative Social Network and Review Content Based Recommender System," J. Ind. Intell. Inf., vol. 4, no. 1, pp. 6975, 2015, doi: 10.12720/jiii.4.1.69-75.

[2] H. Heriyanto et al., "Aplikasi Online Marketplace pada PT . XYZ di Surabaya," no. 031.

[3] R. Suppa dan T. Saldi, "Sistem Informasi Indekos Berbasis Web", PENA TEKNIK: Jurnal Ilmiah Ilmu-Ilmu Teknik Volume 3, Nomor 2, September $2018: 139$ - 146 .

[4] Elgamar Syam, "Rancang Bangun Sistem Informasi Rumah Kost dan Kontrakan Teluk Kuantan", JURNAL TEKNOLOGI DAN OPEN SOURCE, VOL. 1 No. 1, Juni 2018, ISSN ONLINE : 2622-1659.

[5] Arief Budiman, Lara Sri Wahyuni, Suharsono Bantun, Perancangan Sistem Informasi Pencarian Dan Pemesanan Rumah Kos Berbasis Web (Studi Kasus: Kota Bandar Lampung), Jurnal TEKNOKOMPAK, Vol. 13, No. 2, 2019, 24-30. P-ISSN 1412-9663, E-ISSN 2656-3525.

[6] Joysun Agape Sianturi, I Nyoman Piarsa, I Ketut Adi Purnawan, Aplikasi Pencarian dan Penyewaan Rumah Kost Berbasis Web dan Android, MERPATI VOL. 6, NO. 3 DESEMBER 2018 ISSN: 2252-3006.

[7] R. Yustiani and R. Yunanto, "Peran Marketplace Sebagai Alternatif Bisnis Di Era Teknologi Informasi," Komputa J. Ilm. Komput. dan Inform., vol. 6, no. 2, pp. 43-48, 2017, doi: 10.34010/komputa.v6i2.2476.

[8] I. Belkhadir, E. D. Omar, and J. Boumhidi, "An intelligent recommender system using social trust path for recommendations in web-based social networks,” Procedia Comput. Sci., vol. 148, pp. 181-190, 2019, doi: 10.1016/j.procs.2019.01.035. 